\title{
OPEN Analysis of the need for soil moisture, salinity and temperature sensing in agriculture: a case study in Poland
}

\author{
Lech Gałęzewski ${ }^{1 凶}$, Iwona Jaskulska ${ }^{1}$, Dariusz Jaskulski ${ }^{1}$, Arkadiusz Lewandowski ${ }^{2}$, \\ Agnieszka Szypłowska ${ }^{3}$, Andrzej Wilczek ${ }^{3}$ \& Maciej Szczepańczyk ${ }^{4}$
}

Efficient use of scarce water resources is both a marketing objective and an environmental obligation for sustainable agriculture. In modern agricultural production, which is intensive and should at the same time be environmentally friendly, there is a need to monitor soil moisture, salinity and temperature. The aim of the study was to determine the demand of producers of agricultural and horticultural plants for equipment and systems for monitoring soil properties at an individual farm level in regions with highly developed agriculture. A questionnaire survey was conducted among 1087 respondents, also direct interviews in Poland were undertaken. According to the producers' responses, it is important to know soil moisture, salinity and temperature, although currently only about $\mathbf{4 \%}$ of the surveyed farmers have the equipment to evaluate these soil parameters. In their view cost is not the most important obstacle to the purchase of the necessary probes. More important is that the devices should be easy to install and use, and have an easy to use application for data collection, processing and transfer. The current market does not offer solutions that meet these producers expectations. The demand for suitable probes is very high as over $80 \%$ of the farmers declared their willingness to purchase such probes. Technical problems related to the operation and servicing of such equipment were the most frequently mentioned impediments in their use. However, farmers and horticulturists believe that knowledge of their soil properties would allow them to optimize the elements of cultivation technology, including the use of plant irrigation systems, the use of mineral fertilizers and plant protection products.

Climatic conditions shape plant production- not only the yields, but also the area sown, production intensity and selection of technologies ${ }^{1}$. Climatic elements, especially the rainfall and the air temperature are necessary for the proper functioning of the physiological processes of crops $^{2}$, their development and productivity ${ }^{3}$, as well as for shaping the broadly understood properties of soil ${ }^{4}$. Crop plants are sensitive to climate change: deficiency or excess water, or suboptimal temperatures may cause severe abiotic stresses ${ }^{5,6}$. Drought stress causes molecular, biochemical, physiological and morphological changes in plants ${ }^{7}$. Plants then grow smaller organs, e.g. roots, leaves, and also their productivity, biomass and yield are lower ${ }^{8}$. According to Daryanto et al. ${ }^{9}$, a shortage of about $40 \%$ of water in relation to the needs of wheat and maize may reduce the yield of these plants by around $20 \%$ and 39\%, respectively. The results of research conducted on a global scale also indicate the negative impact of an increase in temperature on the yields of the crops most important for feeding humanity. An increase in temperature by one degree Celsius reduces the yield of maize by $7.4 \%$, wheat by $6.0 \%$, rice by $3.2 \%$ and soy by $3.1 \%{ }^{10}$.

Climate change, limited water resources and the high demand for water in agriculture require an increase in the efficiency of water use ${ }^{11,12}$. This can be possible through interdisciplinary research and activities in the field of plant genetics and biology, as well as in measurement technology and agrotechnology ${ }^{13,14}$. The first condition is the monitoring of rainfall and air temperature and other climatic elements that strongly affect the water balance

\footnotetext{
${ }^{1}$ Department of Agronomy, University of Science and Technology in Bydgoszcz, S. Kaliskiego 7, 85-796 Bydgoszcz, Poland. 2Institute of Electronics Systems, Warsaw University of Technology, Nowowiejska 15/19, 00-665 Warsaw, Poland. ${ }^{3}$ Institute of Agrophysics, Polish Academy of Sciences, Doświadczalna 4, 20-290 Lublin, Poland. 'Department of Management Systems and Innovation, Lodz University of Technology, Żeromskiego 116, 90-924 Łódź, Poland. ${ }^{\circledR}$ email: lechgalezewski@op.pl
} 


\begin{tabular}{|l|c|c|c|}
\hline \multirow{2}{*}{ Voivodeship } & \multirow{2}{*}{ Number of communes } & \multicolumn{2}{|l|}{ Respondents } \\
\cline { 3 - 4 } & 2 & Number & $\%$ \\
\hline Lower Silesian & 88 & 595 & 0.46 \\
\hline Kuyavian-Pomeranian & 23 & 26 & 2.41 \\
\hline Lublin & 8 & 22 & 2.04 \\
\hline Lubusz & 8 & 16 & 1.48 \\
\hline Łódź & 7 & 8 & 0.74 \\
\hline Masovian & 31 & 106 & 9.81 \\
\hline Pomeranian & 5 & 9 & 0.83 \\
\hline Warmian-Masurian & 47 & 253 & 23.40 \\
\hline Greater Poland & 26 & 41 & 3.79 \\
\hline West Pomeranian & 245 & 1081 & 100.00 \\
\hline Total & & &
\end{tabular}

Table 1. Geographical and administrative structure of the survey area.

in the soil available to plants ${ }^{15,16}$. There are many sources of data on that topic in the literature ${ }^{17-19}$, however, they are often not very accurate and vary in terms of their measurement methodology ${ }^{20}$. The spatial and temporal monitoring of soil moisture is even more difficult. There are many methods for making direct and indirect evaluations of soil moisture: thermogravimetric direct method, electrometric method, capacitance method, frequency domain reflectometry, time domain reflectometry and the neutron method ${ }^{21,22}$. However, there are few systems for monitoring and collecting data that use a standardized method for soil moisture measurements, as well as for probe data registration, collection and transmission from multiple stations located over a large area. One example of such a system is the International Soil Moisture Network (ISMN) that collects data on soil moisture world-wide ${ }^{23}$.

The lack of accurate information concerning the spatial differentiation of soil water resources available to plants greatly limits the effectiveness and economic legitimacy of sustainable and precision agriculture. The idea of precision agriculture is the application of production means in accordance with the conditions resulting from soil variability, including its moisture, temperature and salinity ${ }^{24,25}$.

In regions with highly developed agriculture and horticulture, producers eagerly use the benefits of technical and technological progress, although in the case of precision agriculture their implementation in Europe is smaller than it is in American or Australian agriculture ${ }^{26}$. In the literature, however, there are few reports on the practical use of devices and systems for the monitoring of spatial and temporal variability of soil properties at a field or farm level. Also, not all modern technologies are accepted among producers, which may be due to a lack of confidence in their effectiveness ${ }^{12,27,28}$. It was thus hypothesized that despite the large market demand for measurement solutions, their popularization in agricultural and horticultural production would require universal, durable, technically uncomplicated, easy-to-use and inexpensive devices. Such requirements can be met by dielectric probes. The knowledge on soil moisture, temperature and salinity is needed by producers to make many decisions regarding not only plant irrigation ${ }^{29,30}$, but also for optimization of fertilization, as well as of dates and methods of tillage, sowing, cultivation measures and plant harvesting.

The purpose of the present work was to determine the demand of producers of agricultural and horticultural plants in regions with highly developed agriculture for devices and monitoring systems of soil properties at the farm level. The research was aimed at understanding the expectations of farmers and horticulturists regarding the functional features of such solutions and their expected usefulness in making production decisions. A critical analysis of the global market of available and easy-to-use dielectric solutions for assessing the continuous changes in soil properties during the vegetation period was also performed.

\section{Material and methods}

The research was carried out in the following stages:

- Formulation of the research problem

- Research method-survey preparation

- Surveying the farmers

- Characterizing respondents' farms (location, acreage, crop structure)- Tables 1, 2, 3

- Assessment of farmers' (respondents) knowledge about the need for and possibilities of soil properties monitoring - Tables 4,8

- A review of the state-of-the-art in relation to probes for assessing moisture, temperature and salinity of soils - Table 5

- Analysis of the needs and expectations of farmers in relation to the probes depending on the actual farming conditions- Tables 6, 7, 9, Figs. 1, 2, 3

- Multivariate analysis of the features that farmers would expect from soil properties monitoring probes'Figs. 4, 5, 6, 7, 8, 9 


\begin{tabular}{|l|c|r|}
\hline \multirow{2}{*}{ Farm area, ha } & \multicolumn{2}{|l|}{ Proportion } \\
\cline { 2 - 3 } & Number & \multicolumn{1}{l|}{$\%$} \\
\hline $1-20$ & 225 & 22.0 \\
\hline $20.1-40$ & 304 & 29.7 \\
\hline $40.1-60$ & 155 & 15.1 \\
\hline $60.1-80$ & 98 & 9.6 \\
\hline $80.1-100$ & 67 & 6.5 \\
\hline $100.1-200$ & 102 & 10.0 \\
\hline $200.1-400$ & 31 & 3.0 \\
\hline $400.1-600$ & 17 & 1.7 \\
\hline $600.1-800$ & 10 & 1.0 \\
\hline $800.1-1000$ & 5 & 0.5 \\
\hline$>1000$ & 11 & 1.1 \\
\hline Total & 1025 & 100.0 \\
\hline
\end{tabular}

Table 2. Area structure of the examined agricultural and horticultural farms.

\begin{tabular}{|c|c|c|c|c|c|}
\hline \multirow[b]{3}{*}{ Crops } & \multirow[b]{3}{*}{ Irrigation } & \multicolumn{4}{|l|}{ Presence } \\
\hline & & \multicolumn{2}{|l|}{ Yes } & \multicolumn{2}{|l|}{ No } \\
\hline & & Number & $\%$ & Number & $\%$ \\
\hline \multirow{3}{*}{ Cereals } & No & 960 & 89 & 8 & 73 \\
\hline & Yes & 116 & 11 & 3 & 27 \\
\hline & Total & 1076 & 100 & 11 & 100 \\
\hline \multirow{3}{*}{ Oilseed rape } & No & 563 & 92 & 405 & 86 \\
\hline & Yes & 51 & 8 & 68 & 14 \\
\hline & Total & 614 & 100 & 473 & 100 \\
\hline \multirow{3}{*}{ Beet } & No & 681 & 90 & 287 & 88 \\
\hline & Yes & 79 & 10 & 40 & 12 \\
\hline & Total & 760 & 100 & 327 & 100 \\
\hline \multirow{3}{*}{ Potato } & No & 256 & 83 & 712 & 91 \\
\hline & Yes & 52 & 17 & 67 & 9 \\
\hline & Total & 308 & 100 & 779 & 100 \\
\hline \multirow{3}{*}{ Vegetables } & No & 79 & 56 & 889 & 94 \\
\hline & Yes & 63 & 44 & 56 & 6 \\
\hline & Total & 142 & 100 & 945 & 100 \\
\hline \multirow{3}{*}{ Fruit trees } & No & 40 & 71 & 928 & 90 \\
\hline & Yes & 16 & 29 & 103 & 10 \\
\hline & Total & 56 & 100 & 1031 & 100 \\
\hline \multirow{3}{*}{ All } & No & 968 & 89 & - & - \\
\hline & Yes & 119 & 11 & - & - \\
\hline & \begin{tabular}{|l|} 
Total \\
\end{tabular} & 1087 & 100 & - & - \\
\hline
\end{tabular}

Table 3. Crop structure and plant irrigation on agricultural and horticultural farms.

The source material consisted of the results of the survey and face-to-face interviews. The respondents consisted of owners or managers of farms in Poland. The respondents were selected randomly during the most important national agricultural meetings in the summer of 2018. 1087 correctly completed questionnaires were obtained, which is a representative sample. The respondents had farms located in 246 communes in 10 voivodeships (provinces) that have the most developed agricultural and horticultural production in Poland. The selection of the research area, the diversity of respondents and the economic potential of their farms enables a generalization of the obtained results to many agricultural regions in Europe and in the world.

The survey questionnaire and the interview scenario included questions about the location of the farm, its area, the species structure of cultivated plants and the use of crop irrigation. The questionnaire also included questions about the farmers' knowledge of the impact of soil properties on the applicability and effectiveness of cultivation elements. The resulting data was subjected to mathematical and statistical analysis. By grouping results according to a given criterion, incorrectly filled questionnaires were removed. Excel 2016 spreadsheet (Microsoft Corporation) and the statistical package Statistica 12.5 (StatSoft Inc.) were used to analyse the results. Multivariate analyzes were also performed. The results of the surveys and interviews were analyzed in three groups of 


\begin{tabular}{|l|l|l|l|}
\hline Question & Answer & Number & \% \\
\hline \multirow{4}{*}{ Is knowledge of soil moisture, important? } & Yes & 1009 & 96.7 \\
\cline { 2 - 4 } & No & 35 & 3.3 \\
\cline { 2 - 4 } & Total & 1044 & 100 \\
\hline \multirow{4}{*}{ Is soil moisture currently monitored using probes? } & Yes & 45 & 4.3 \\
\cline { 2 - 4 } & No & 1008 & 95.7 \\
\cline { 2 - 4 } & Total & 1053 & 100 \\
\hline \multirow{3}{*}{ Declaration of willingness to test/use devices for monitoring of soil properties } & Yes & 878 & 83.2 \\
\cline { 2 - 4 } & No & 177 & 16.8 \\
\cline { 2 - 4 } & Total & 1055 & 100 \\
\hline
\end{tabular}

Table 4. Assessment of the need and current state of monitoring of soil properties, including soil moisture.

\begin{tabular}{|c|c|c|c|c|c|c|c|}
\hline \multirow[b]{2}{*}{ Probe } & \multirow[b]{2}{*}{ Measurement principle } & \multicolumn{2}{|c|}{$\begin{array}{l}\text { Independence } \\
\text { of soil moisture } \\
\text { measurement on }\end{array}$} & \multirow[b]{2}{*}{ Soil salinity measurement } & \multirow{2}{*}{$\begin{array}{l}\text { Soil temperature } \\
\text { measurement }\end{array}$} & \multirow[b]{2}{*}{ Cable connections } & \multirow[b]{2}{*}{ Wireless network } \\
\hline & & Salinity & Texture & & & & \\
\hline E-Test TDR/MUX/mpts & TDR & Yes & Yes $^{*}$ & Yes & Yes & Yes & Yes \\
\hline Acclima True TDR-315 & TDR & Yes & Yes $^{*}$ & Yes & Yes & Yes & No \\
\hline FieldScout TDR 150 & TDR & Yes & Yes $^{*}$ & Yes & Yes & Yes & Yes \\
\hline HYDRA 100 Scout & CAP & No & $\mathrm{No}^{* *}$ & Yes & Yes & No & Yes \\
\hline WaterScout SMEC 300 & CAP & No & $\mathrm{No}^{* *}$ & Yes & Yes & Yes & No \\
\hline Campbell Scientific CS655 & TDR-like & Yes & Yes $^{*}$ & Yes & Yes & Yes & No \\
\hline Decagon 5TE & CAP & No & $\mathrm{No}^{* *}$ & Yes & Yes & Yes & No \\
\hline Delta-T ML3 probe & CAP & No & $\mathrm{No}^{* *}$ & No & Yes & Yes & No \\
\hline
\end{tabular}

Table 5. Dielectric properties of the probes selected for evaluation of soil properties. ${ }^{\star}$ For most soils, standard calibration provides sufficient measurement accuracy. Individual calibration may be beneficial for soils with a high content of clay fraction or organic matter. ${ }^{*}$ Producers may supply several calibration functions for various soil types. It is also advised to perform an individual calibration of the probe for the tested soil type to achieve good measurement accuracy. TDR time-domain-reflectometry, measurement of apparent dielectric permittivity. Moisture measurement is virtually independent of soil salinity (in the salinity range of normal agricultural soils), soil texture influence is usually minimal and negligible for most mineral soils in agricultural applications. For most soils, standard calibration provides sufficient measurement accuracy. Individual calibration may be beneficial for soils with a high content of clay fraction or organic matter. CAP measurement of capacitance or impedance of sensor electrodes inserted into soil at a specific frequency, usually not higher than $100 \mathrm{MHz}$. The lower the measurement frequency that is used the greater is the potential influence of soil salinity and texture. Producers may supply several calibration functions for various soil types. It is also advised to perform an individual calibration of the sensor for the tested soil type to achieve good measurement accuracy.

respondents: territorial - voivodship, area - farm size, and crop structure - species and groups of crops. In the first group, there were 7 cases (with over 10 respondents in each voivodeship), in the second group-11 cases, and in the third - 7 cases. The variables were the functional and technical features ( 16 traits) of probes for monitoring soil moisture and salinity as well as the agronomic functionalities of these probes that were expected by farmers to be useful for optimization of plant production. The percentages of respondents' positive responses were treated as values for individual features and were standardized prior to cluster analysis and principal component analysis. The result of the cluster analysis is presented as a dendrogram after using Ward's method for grouping cases. The results of the principal component analysis (two principal components) are presented as a projection of primary variables on the plane.

Characteristics of the surveyed population. The largest number of surveys were carried out in regions with well-developed field agricultural and horticultural production-vegetable growing, fruit growing, i.e. in Kuyavian-Pomeranian voivodship - 55.0\% of surveys, Greater Poland $-23.4 \%$, Pomeranian-9.8\%, as well as in West Pomeranian, Lublin, Lubusz and Łódź-each more than $1 \%$ (Table 1).

The surveys covered farms diversified in terms of their area, the type of agricultural land and the crop structure. The test sample included both small farms and large agricultural enterprises with several thousand of ha of agricultural land. The largest group was family farms with an area of 20-40 ha, which represented close to $30 \%$ of the tested sample (Table 2). The percentage of large (>100 ha) and very large (>1000 ha) farms was higher than it would have been if based on their share in the area structure of agricultural holdings in Poland. This is a consequence of the data collection methodology. The survey questionnaire and direct interviews were carried 


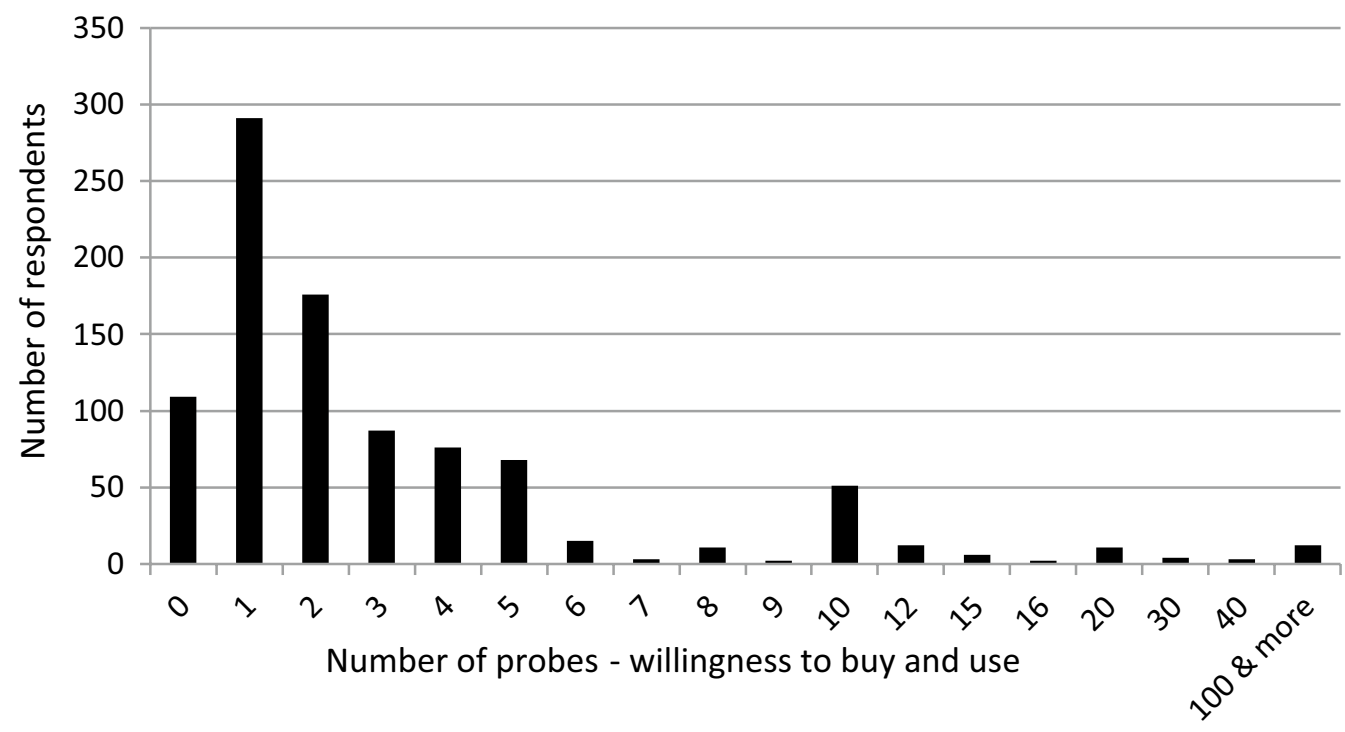

Figure 1. Number of respondents declaring willingness to buy and use a certain number of probes.

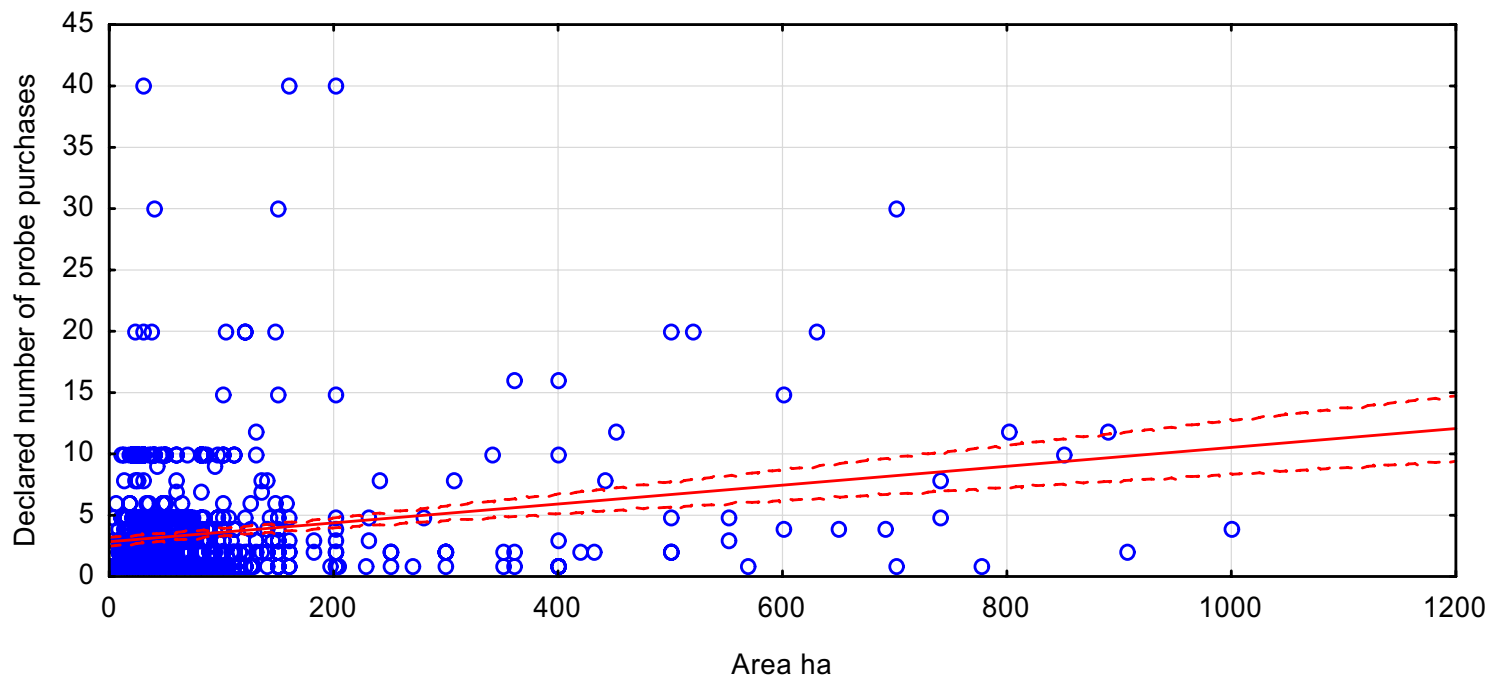

Figure 2. Relationship between the size of the farm and the declared number of purchases and use of probes.

out mainly among the owners and users of farms with a high production potential and, to a lesser extent, in small farms producing for self-supply of the family and not having a commercial character. On the other hand, such a disproportion in the surveyed area groups of farms is justified, since farms with larger areas constitute more of a potential market for devices for monitoring the soil moisture, temperature and salinity.

A particularly important group of the respondents interested in soil moisture monitoring were the owners of farms who grow commodity crops while applying irrigation. Thus, farms were grouped based on the presence (Yes, No) of irrigation systems and cultivated plants. Only 11 farms (1.01\%) did not grow basic cereals. These were farms specialized in the cultivation of vegetables, maize or other crops (Table 3). Irrigation was used mainly in horticultural crops-in vegetables-on $29 \%$ of farms, orchards - $44 \%$ of farms and potatoes - $17 \%$. In Poland, however, farms cultivating basic agricultural crops, such as cereals, oilseed rape and sugar beet, dominate. In the study group, these crops constituted $99.0 \%, 56.5 \%$ and $69.9 \%$ of holdings, respectively, and about $10 \%$ of them apply irrigation.

Direct interviews were conducted in 15 locations with producers of agricultural, horticultural and special crops. These were farms of various sizes and production types: three large-area farms (450-1400 ha) mainly engaged in the production of agricultural crops; three large-area (600-1100 ha) and three smaller (20-80 ha) farms focused on the production of vegetables; four fruit farms; as well as two farms growing hops. 


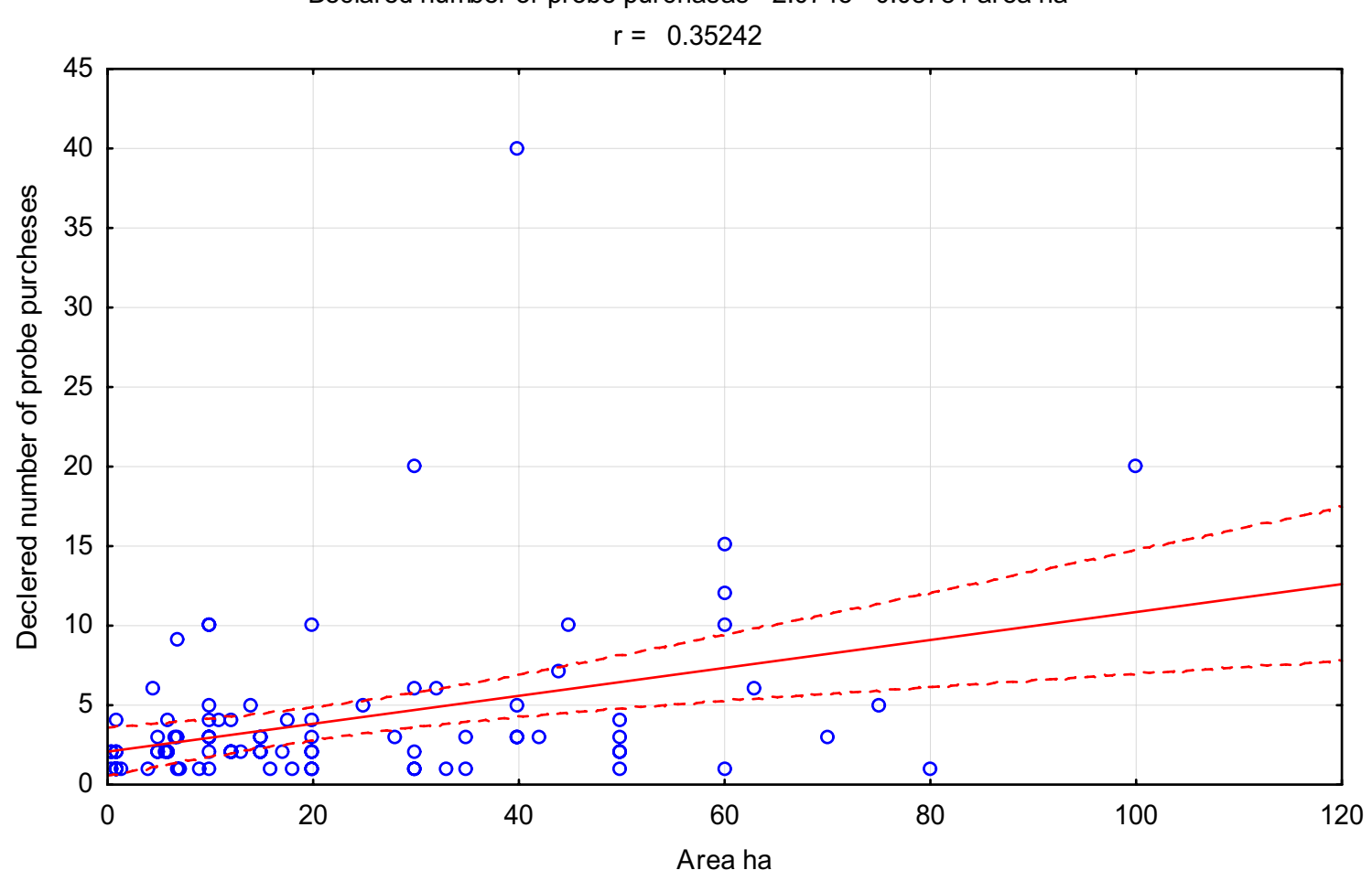

Figure 3. Relationship between irrigated area on the farm and the declared number of purchase and use of probes.

\begin{tabular}{|c|c|c|c|c|c|c|c|c|}
\hline \multirow[b]{3}{*}{ Farm element } & \multicolumn{8}{|c|}{ Occurrence of elements } \\
\hline & \multicolumn{4}{|l|}{ Yes } & \multicolumn{4}{|l|}{ No } \\
\hline & \begin{tabular}{|l|}
$\begin{array}{l}\text { Number of } \\
\text { respondents }\end{array}$ \\
\end{tabular} & $\begin{array}{l}\text { Declaration of use of } \\
\text { the device }\end{array}$ & $\%$ & $\begin{array}{l}\text { Mean number of } \\
\text { probes }\end{array}$ & \begin{tabular}{|l} 
Number of \\
respondents
\end{tabular} & $\begin{array}{l}\text { Declaration of use of } \\
\text { the device }\end{array}$ & $\%$ & $\begin{array}{l}\text { Mean number of } \\
\text { probes }\end{array}$ \\
\hline Irrigation & 119 & 99 & 83.2 & 4.15 & 968 & 723 & 74.7 & 3.51 \\
\hline Cereals & 1076 & 814 & 75.7 & 3.55 & 11 & 8 & 72.7 & 7.50 \\
\hline Oilseed rape & 614 & 514 & 83.7 & 3.63 & 473 & 308 & 65.1 & 3.51 \\
\hline Beet & 760 & 582 & 76.6 & 3.49 & 327 & 240 & 73.4 & 3.81 \\
\hline Potato & 308 & 231 & 75.0 & 3.53 & 779 & 591 & 75.9 & 3.61 \\
\hline Vegetables & 142 & 120 & 84.5 & 3.43 & 945 & 702 & 74.3 & 3.61 \\
\hline Fruit trees & 56 & 41 & 73.2 & 2.68 & 1031 & 781 & 75.8 & 3.63 \\
\hline
\end{tabular}

Table 6. Declaration of demand for devices monitoring soil properties depending on the characteristics of the farm.

All methods were carried out in accordance with relevant guidelines and regulations. Informed consent was obtained from all subjects-the questionnaires were anonymous. All respondents were of legal age. None of the experimental protocols required approval by licensing committees or institutions.

\section{Results and discussion}

The survey results indicate that for most farmers and horticulturists in Poland, i.e. for $96.7 \%$ of respondents, the knowledge of soil properties, including moisture, is important, although currently only $4.3 \%$ of them monitor soil moisture in their farms (Table 4). It follows from this data that farmers are aware of the impact of soil moisture on the conditions and effects of plant cultivation, but they have no possibility to make an ongoing assessment and analysis. Such a situation exists not only in Poland, but also in other countries. Even innovative and welldeveloped soil moisture monitoring systems on a global scale have limited application in individual farms ${ }^{23,29}$. Farmers expect easy-to-use devices that monitor soil moisture for the purpose of making optimal decisions when irrigating arable crops ${ }^{30}$. Similar expectations of Polish farmers were confirmed by the high percentage of respondents $-83.2 \%$, who declared the willingness to test such devices in their farms prior to purchasing them.

Our analysis of the available commercial solutions on the market indicates that the currently available monitoring systems are imperfect and difficult in direct use on a farm, e.g. soil moisture measurement is dependent 


\begin{tabular}{|l|c|c|c|c|}
\hline \multirow{2}{*}{ Voivodeship } & \multicolumn{4}{|l}{ Declaration of use } \\
\cline { 2 - 5 } & Yes & \multicolumn{2}{l|}{ No } \\
\cline { 2 - 5 } & Number & $\%$ & Number & $\%$ \\
\hline Lower Silesian & 2 & 40 & 3 & 60 \\
\hline Kuyavian-Pomeranian & 446 & 75 & 149 & 25 \\
\hline Lublin & 22 & 85 & 4 & 15 \\
\hline Lubusz & 13 & 59 & 9 & 41 \\
\hline Lódź & 12 & 75 & 4 & 25 \\
\hline Mazovian & 8 & 100 & 0 & 0 \\
\hline Pomeranian & 83 & 78 & 23 & 22 \\
\hline Warmian-Masurian & 7 & 78 & 2 & 22 \\
\hline Greater Poland & 187 & 74 & 66 & 26 \\
\hline West Pomeranian & 40 & 98 & 1 & 2 \\
\hline Total/mean & 820 & 76 & 261 & 24 \\
\hline
\end{tabular}

Table 7. Geographic and administrative diversity of the willingness to use devices for monitoring soil properties.

\begin{tabular}{|c|c|c|c|}
\hline Agricultural treatment & Declaration & Number & $\%$ \\
\hline \multirow{3}{*}{ Date of starting field works } & No & 48 & 9.2 \\
\hline & Yes & 475 & 90.8 \\
\hline & Total & 523 & 100.0 \\
\hline \multirow{3}{*}{ Sowing date } & No & 32 & 6.1 \\
\hline & Yes & 490 & 93.9 \\
\hline & Total & 522 & 100.0 \\
\hline \multirow{3}{*}{ Sowing depth } & No & 119 & 24.6 \\
\hline & Yes & 365 & 75.4 \\
\hline & Total & 484 & 100.0 \\
\hline \multirow{3}{*}{ Soil cultivation method } & No & 90 & 18.6 \\
\hline & Yes & 394 & 81.4 \\
\hline & Total & 484 & 100.0 \\
\hline \multirow{3}{*}{ Fertilization method/rate } & No & 127 & 25.9 \\
\hline & Yes & 363 & 74.1 \\
\hline & Total & 490 & 100.0 \\
\hline \multirow{3}{*}{ Application of plant protection products } & No & 132 & 28.0 \\
\hline & Yes & 339 & 72.0 \\
\hline & Total & 471 & 100.0 \\
\hline \multirow{3}{*}{ Irrigation time/dose of water } & No & 129 & 40.6 \\
\hline & Yes & 189 & 59.4 \\
\hline & Total & 318 & 100.0 \\
\hline \multirow{3}{*}{ Irrigation time/dose of water ${ }^{*}$} & No & 5 & 17.2 \\
\hline & Yes & 24 & 82.8 \\
\hline & Total & 29 & 100.0 \\
\hline
\end{tabular}

Table 8. Assessment of the impact of soil properties on the optimization of agrotechnical proceduresfarmers’ declarations. *Only respondents declaring crop irrigation.

on its salinity and temperature, measuring probes require connections using a cable and have limited wireless connection options available and no battery power supply. Only one of the solutions cited is completely wireless (HYDRA 100 Scout). It uses, however, capacitive probes, whose measurements are affected by a systematic error resulting from the influence of salinity and soil texture (Table 5).

Despite an awareness of the present technical limitations, the majority (88.4\%) of respondents declared their willingness to purchase and use one or more probes to assess the moisture, salinity and temperature of the soil in their farms. A condition was that the probe manufacturers eliminate current design imperfections (Fig. 1). In total, the sample of surveyed farmers declared a demand for 2905 probes, and most of them said they would build a system for monitoring soil properties in their farm in the future. The largest groupof the respondents, $31 \%$, declared an interest to purchase only one probe, but $18.7 \%$ said two probes and about $10 \%$ of respondents declared an interest to purchase 10 or more probes. This number of devices could make it possible to build a 


\begin{tabular}{|c|c|c|c|c|c|c|}
\hline \multirow[b]{3}{*}{ Device characteristic } & \multicolumn{6}{|c|}{ Characteristic significance } \\
\hline & \multicolumn{2}{|c|}{ Not important } & \multicolumn{2}{|c|}{ Important } & \multicolumn{2}{|c|}{ Very important } \\
\hline & Number & $\%$ & Number & $\%$ & Number & $\%$ \\
\hline Low price & 73 & 7.04 & 526 & 50.7 & 438 & 42.2 \\
\hline Measurement accuracy & 28 & 2.73 & 386 & 37.7 & 611 & 59.6 \\
\hline Measurement depth $0-15 \mathrm{~cm}$ & 77 & 8.38 & 533 & 58.0 & 309 & 33.6 \\
\hline Depth $0-15 \mathrm{~cm}$ and $15-30 \mathrm{~cm}$ & 88 & 9.21 & 523 & 54.8 & 344 & 36.0 \\
\hline Reliability and damage resistance & 43 & 4.37 & 395 & 40.2 & 545 & 55.4 \\
\hline Easy assembly and service & 62 & 6.13 & 462 & 45.7 & 487 & 48.2 \\
\hline Wireless data transmission & 187 & 18.9 & 518 & 52.5 & 282 & 28.6 \\
\hline Estimation of water dosage & 134 & 14.8 & 464 & 51.2 & 308 & 34.0 \\
\hline Estimation of water dosage ${ }^{*}$ & 8 & 7.84 & 44 & 43.1 & 50 & 49.0 \\
\hline Irrigation automation ${ }^{\star}$ & 21 & 22.1 & 38 & 40.0 & 36 & 37.9 \\
\hline Irrigation automation & 214 & 24.5 & 436 & 49.9 & 224 & 25.6 \\
\hline
\end{tabular}

Table 9. Required features of devices for soil properties monitoring according to farmers' expectations. ${ }^{\star}$ Only respondents declaring crop irrigation.

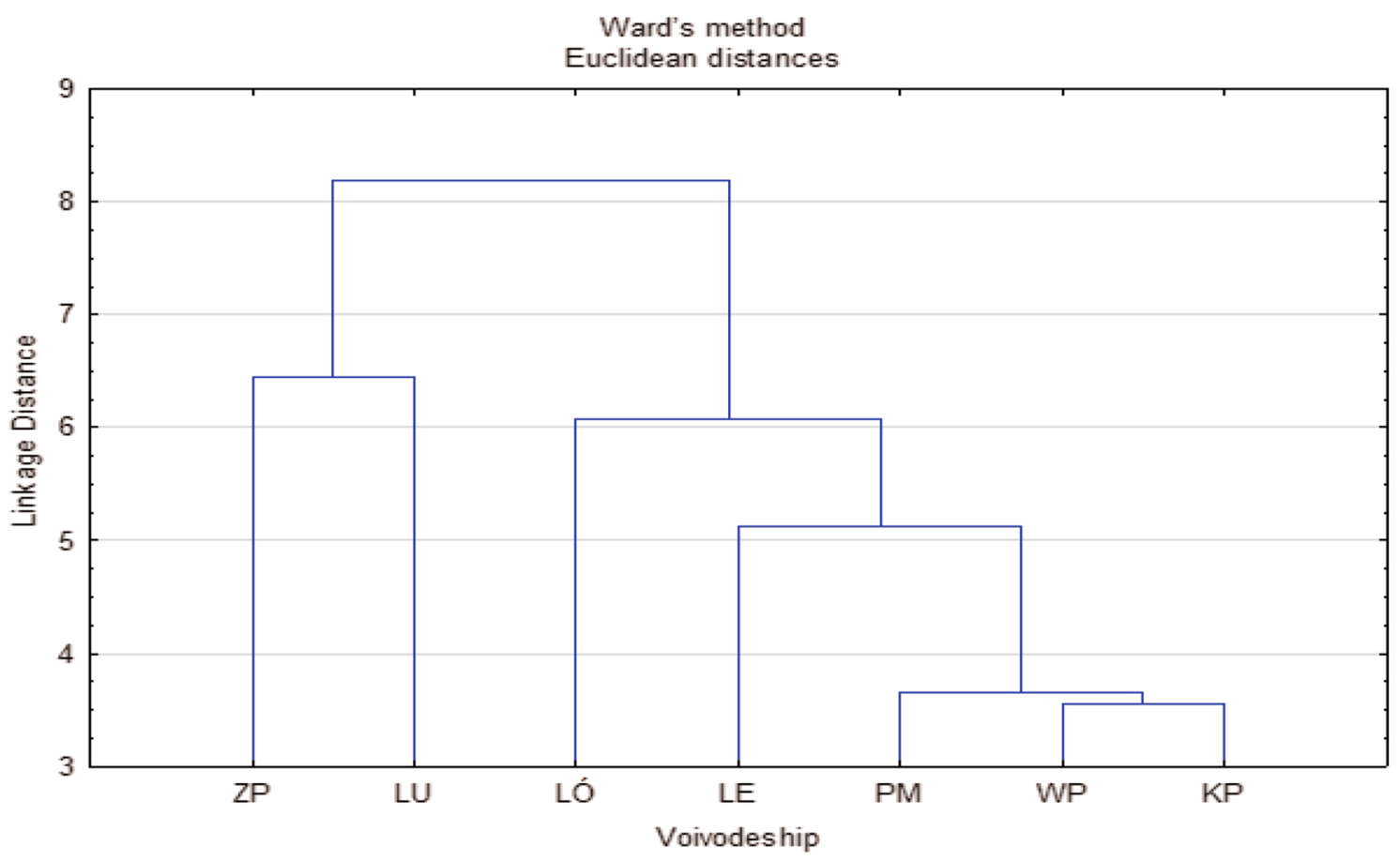

Figure 4. Clusters of voivodeships with similar farmers' expectations regarding the features of probes for the assessment of soil moisture and salinity. Voivodeship: KP-Kuyavian-Pomeranian, LE-Lublin, LU-Lubusz, LÓ-Łódź, PM-Pomeranian, WP-Greater Poland, ZP-West Pomeranian.

measurement network for monitoring soil properties in a farm. The obtained declarations of purchase and use indicates the farmers' desire for simple, easy-to-use devices for assessing soil moisture, salinity and temperature. According to the results of studies conducted by Jury and Vaux ${ }^{31}$ and Regan et al. ${ }^{32}$, such a high demand for soil moisture monitoring systems may also be a result of the growing economic and ecological awareness of agricultural producers. The consumption of water in agricultural production amounts to approximately $75 \%$ of the available global freshwater resources, and it is increasing. Therefore, conserving water is a duty of everyone, including farmers regardless of their type and size of production.

Although a statistically significant relationship was found between the surface area of the farm and the declared number of devices for purchase and use, the correlation coefficient $r=0.223$ was low (Fig. 2). Therefore, the size of the farm was not a very important premise that farmers followed when declaring their willingness to purchase equipment for the ongoing assessment of soil properties. Such results confirm, therefore, a high awareness of farmers on the impact of soil moisture, salinity and temperature on production efficiency and the environment. This is also indicated by a stronger relationship between the irrigated area within the farm and the declared number of probes to be used. There the correlation coefficient was $r=0.352$ (Fig. 3 ). This is justified because irrigation is a high-cost element of cultivation technology, and its effectiveness depends on the properties 


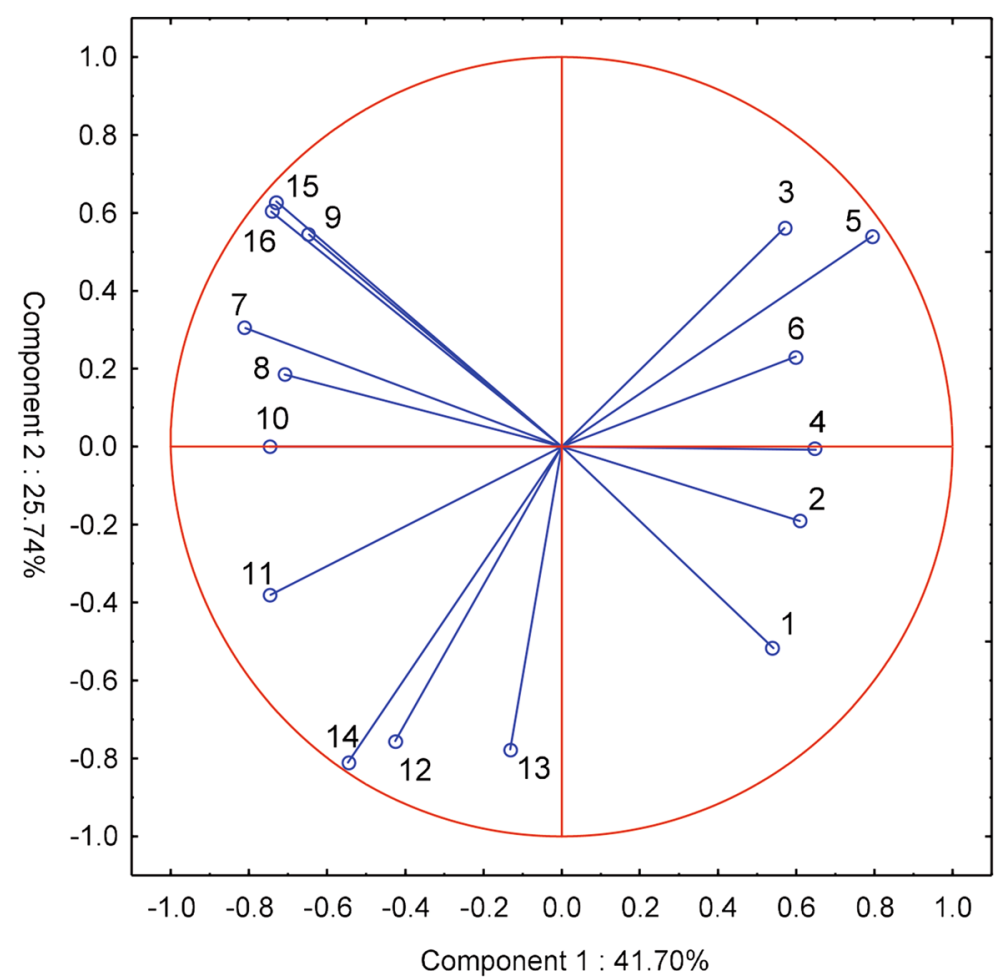

Figure 5. Main components of farmers' expectations in voivodeships with regard to the possibility of using probes to optimize agrotechnical treatments: 1-date of commencement of field works, 2-sowing date, 3-sowing depth, 4-method of soil cultivation, 5-method and dose of fertilization, 6-application of plant protection products, 7 -dates of fertilization. With regard to performance characteristics of the probes: 8-price, 9-measurement accuracy, 10-measurement range $0-15 \mathrm{~cm}, 11$-measurement range $0-30 \mathrm{~cm}$, 12-reliability and resistance to damage, 13-easy installation and operation, 14-sending results to a smartphone/computer, 15-information about the dose of water for irrigation, 16-measurement data used to automate irrigation.

of the soil. Therefore, the knowledge of its moisture, but also temperature and salinity, allows one to optimize the time of irrigation, the dose of water and coexisting fertilizing. The spatial variability of soil also contributes to the need for accurate monitoring of soil properties in an irrigated field ${ }^{33}$.

The characteristics of an agricultural holding, i.e. the structure of the cultivated plants and the use of an irrigation system, did not have a major impact on farmers' interest in the use of equipment for an ongoing assessment of soil properties. This interest was high and varied from 65.1 to $84.5 \%$, depending on the farm characteristics (Table 6). In the group of farmers using irrigation systems, as many as $83 \%$ indicated the willingness to have an average of 4.15 probes in their farms. Also, in the group of farms not currently using irrigation, the interest in these devices was high with $74 \%$ of farmers declaring a potential average use of 3.51 probes. In farms not cultivating cereals, and thus having other intensive crops, the interest in these devices was the highest with an average of 7.5 probes per farm. The data in Table 6 show that a relatively high interest in devices for monitoring soil moisture, salinity and temperature was demonstrated by farmers growing various groups of plants. However, the largest number of such declarations were made by farmers growing vegetables - $84.5 \%$. Farmers growing oilseed rape were also more interested in using probes than those who do not grow oilseed rape. It follows, therefore, that those most interested in the use of these devices were farmers growing crops generating potentially large profits, but requiring favourable soil conditions the correction of which is possible by agricultural practices when the soil moisture, salinity and temperature are known.

The declarations of purchase and use of devices for the assessment of soil properties were regionally diversified (Table 7). All surveyed farmers and horticulturists from the Mazovian voivodeship expressed a need to have such devices in their farms. It should be noted that this is the region of Poland with the largest concentration of orchards and with many vegetable farms. In the West Pomeranian voivodeship, in turn, there are large-scale agricultural farms, whose users have a high awareness of spatial and temporal diversification of soil properties and their impact on the effectiveness of agricultural practices ${ }^{34}$. These conditions were also emphasized by farmers in direct interviews.

More than $90 \%$ of farmers in the surveys declared that the knowledge of soil moisture, temperature and salinity is helpful in determining the starting date of field works and sowing (Table 8). In their opinion, the influence of soil properties on other cultivation practices, such as fertilization, plant protection and irrigation, is also high. Such reasoning is fully justified, because the soil properties determine its bearing capacity and traction capacity for tractors and agricultural machinery without adversely affecting the soil structure ${ }^{35,36}$. Soil temperature and moisture, in turn, are the basic factors of seed germination and plant growth ${ }^{37-39}$. 
Ward's method

Euclidean distances

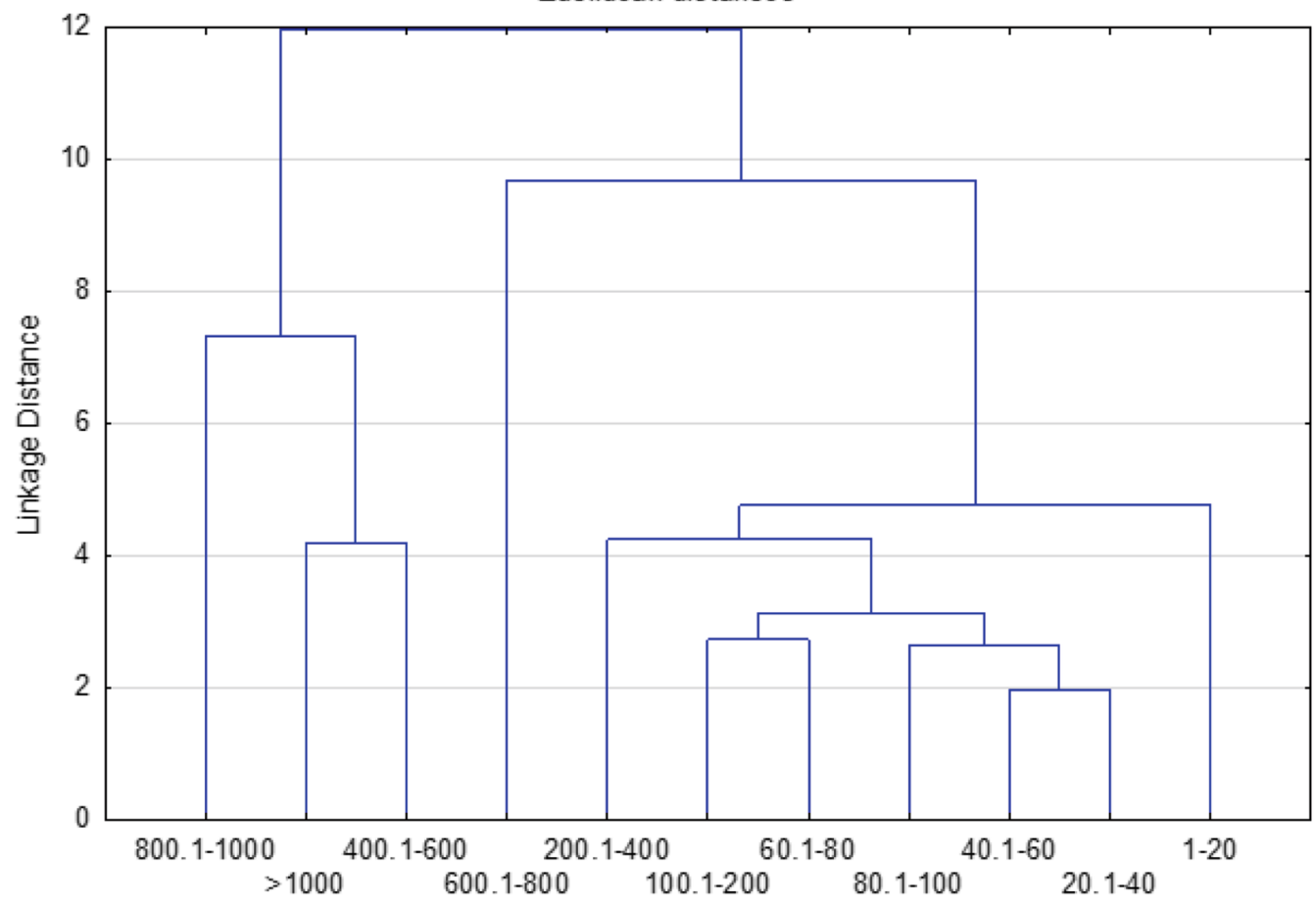

Figure 6. Clusters of farms of different areas (ha) with similar expectations of farmers in terms of the features of the soil moisture and salinity probes.

Most farmers have recognized that the most important features that characterize a good soil monitoring device are measurement accuracy and reliability. Also important are the ability to assess soil properties at various depths, wireless data transmission and estimation of the water dose during irrigation based on the obtained soil moisture and temperature (Table 9). According to farmers, the price of equipment is also important although it is not the most important.

Farmers' expectations regarding the performance features of the probes and the possibility of using them in the optimization of agrotechnical treatments were most similar in the Kuyavian-Pomeranian (KP), Greater Poland (WP), and Pomeranian (PM) voivodships. These are regions of Poland with typical family farms conducting commercial crop and livestock production with the inclusion of horticultural production. Farmers from the Lubusz (LU) and West Pomeranian (ZP) voivodships-regions of north-western Poland with large-scale farms focused mainly on field crop production-had the most different expectations for the probes (Fig. 4).

According to the expectations of farmers from their respective voivodeships of Poland, the most important features are the possibility of using the probes to optimize the method and dose of fertilization ${ }^{5}$ and the choice of the date of fertilization of plants ${ }^{7}$, which is not correlated with the aforementioned characteristic-it is the greatest contribution to the first component. According to the respondents, the operational features of the probes are also important, such as their reliability, ease of use, transfer of results to a smartphone/computer, and using the results for irrigation of plants ${ }^{12-16}$-it is the second main component (Fig. 5).

Farmers' expectations regarding the functionality of the probes were related to the size of their farms (Fig. 6). The expectations of the farmers of the smallest farms (up to $20 \mathrm{ha}$ ) and large farms (of 800-1000 ha) were the most divergent. The requirements of owners of farms with a smaller area, up to 400 ha, differed from the requirements of farmers running production on farms with a large area.

Farmers expected, above all, that the probes would facilitate the use of plant protection products ${ }^{6}$ and that they would be reliable, easy to use, and reported results online ${ }^{12-14}$ - these are the first main component (Fig. 7). Probes should also optimize the choice of the date of commencing field works ${ }^{1}$ and fertilization of plants ${ }^{5,7}$ with the ability to measure soil moisture and salinity both in the $0-15 \mathrm{~cm}$ and $0-30 \mathrm{~cm}$ layer ${ }^{9,10}$-these are the second main component.

The dendrogram (Fig. 8) shows that farmers' expectations as to the performance of the probes depended on the crops they were growing. The first group were farmers growing agricultural crops such as cereals, beetroot, rape and others, and the second group were potato growers. Horticulturists growing vegetables and fruit trees are separate groups.

Farmers cultivating various groups of plants declared that probes monitoring soil moisture and salinity should help in choosing the optimal date of field works ${ }^{1}$, including the date of sowing ${ }^{2}$, the method of soil cultivation ${ }^{4}$ and the method and dose of fertilization ${ }^{5}$ - these are the first main component. In addition, the probes should optimize the fertilization date ${ }^{7}$ and plant irrigation ${ }^{15,16}$ on the basis of information sent to a smartphone/computer $^{14}$ - these are the second component (Fig. 9). 


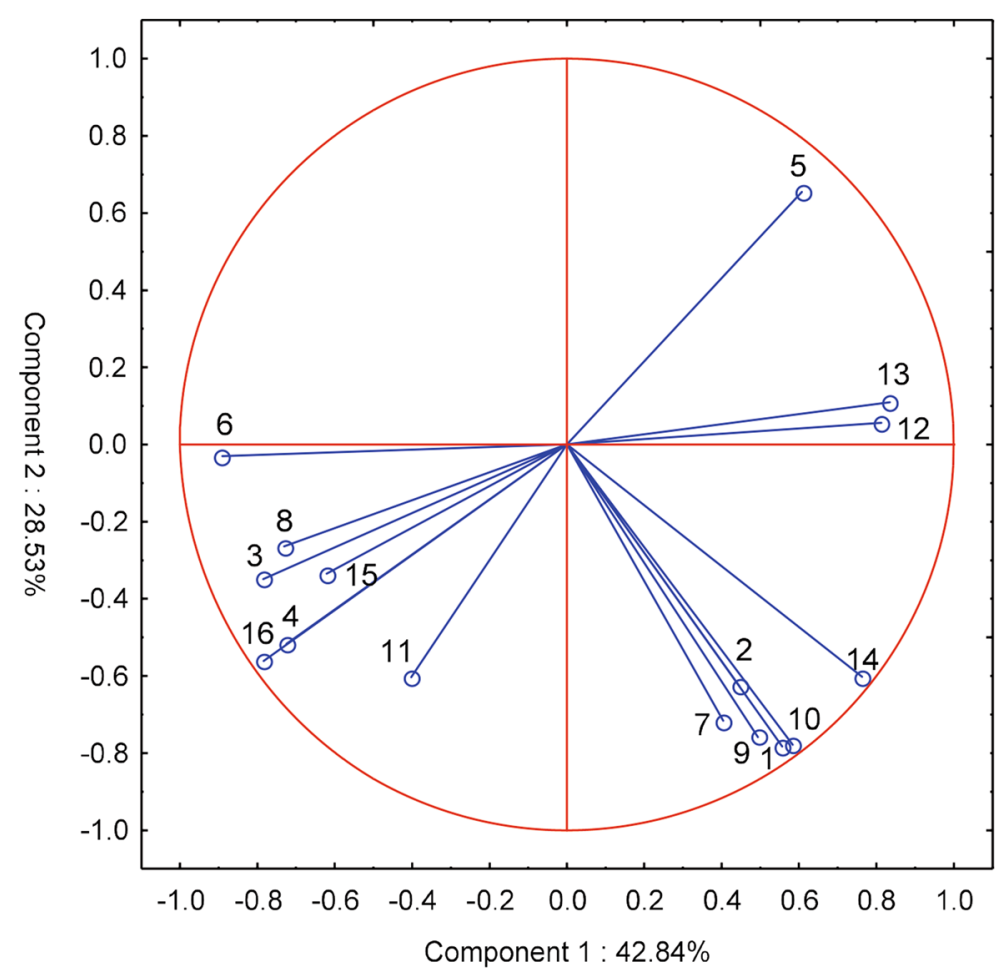

Figure 7. Main components of expectations of owners of farms with different areas with regard to the possibility of using probes to optimize agrotechnical treatments: 1-date of commencement of field works, 2-date of sowing, 3-sowing depth, 4-method of soil cultivation, 5-method and fertilization dose, 6-application of plant protection products, 7-dates of fertilization. With regard to functional features of the probes: 8-price, 9-measurement accuracy, 10 -measurement range $0-15 \mathrm{~cm}, 11$-measurement range $0-30 \mathrm{~cm}, 12$-reliability and resistance to damage, 13-easy installation and operation, 14-sending results to a smartphone/computer, 15-information on the dose of water for irrigation, 16-measurement data used to automate irrigation.

Ward's method

Euclidean distances

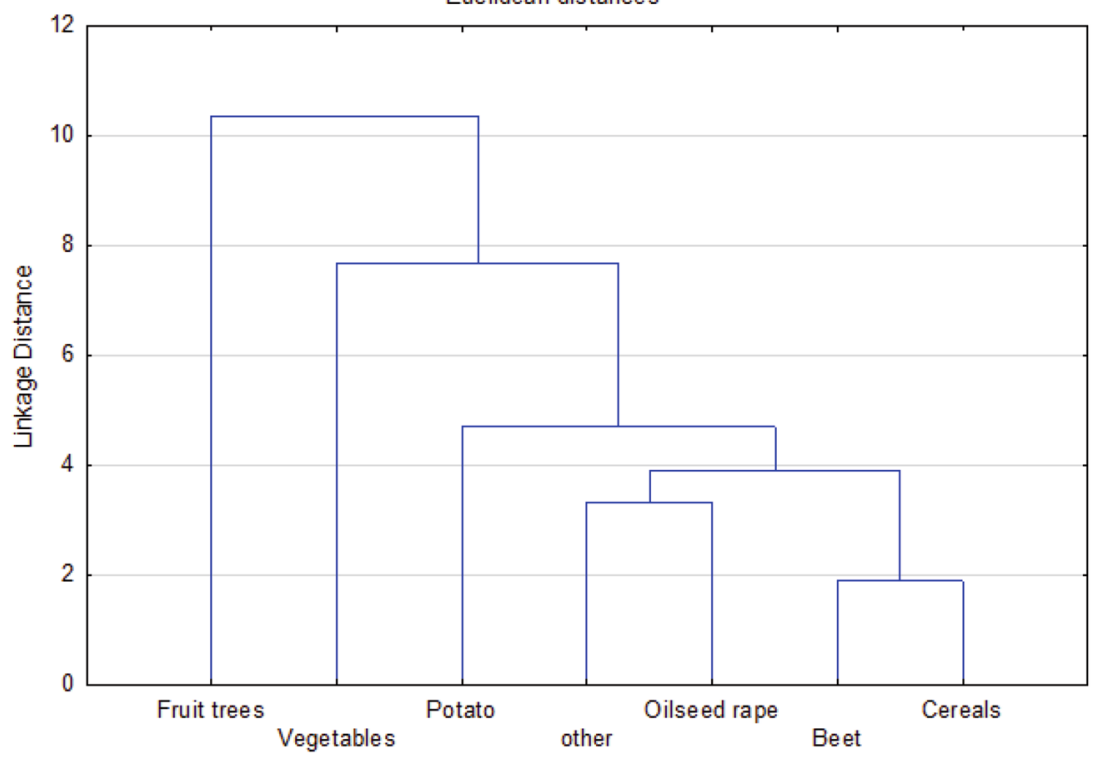

Figure 8. Clusters of groups of plants cultivated by farmers with similar expectations regarding the features of soil moisture and salinity probes. 


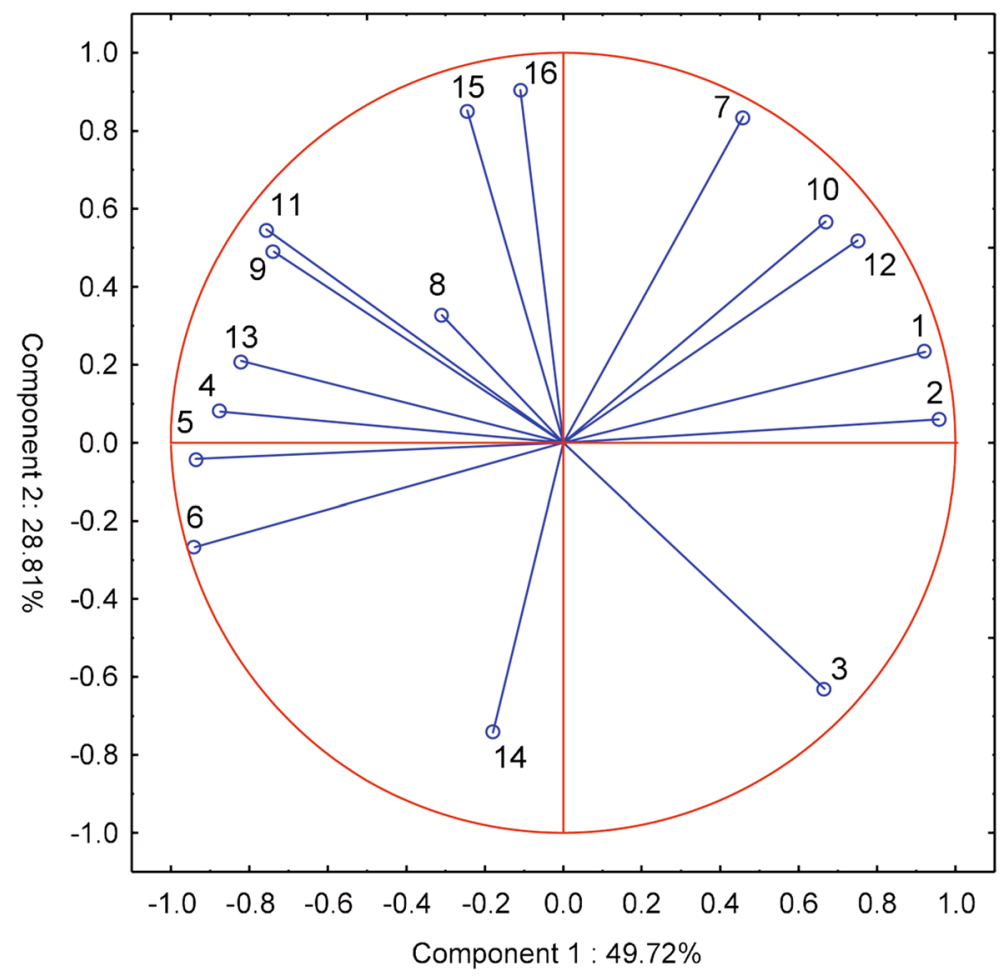

Figure 9. Main components of the expectations of farmers cultivating various groups of plants with regard to the possibility of using probes to optimize agrotechnical treatments: 1-date of commencement of field works, 2-sowing date, 3-sowing depth, 4-soil cultivation, 5-method and fertilization dose, 6-application of plant protection products, 7 -dates of fertilization. With regard to functional features of the probes: 8-price, 9-measurement accuracy, 10-measurement range $0-15 \mathrm{~cm}, 11$-measurement range $0-30 \mathrm{~cm}, 12$-reliability and resistance to damage, 13-easy installation and operation, 14-sending results to a smartphone/computer, 15-information about the dose of water for irrigation, 16-measurement data used to automate irrigation.

Direct interviews conducted with a representative sample of farmers confirmed the results of the survey. Regardless of the production sector (agriculture, horticulture), farm size or region, farmers emphasized the need for ongoing monitoring of soil properties, mainly moisture, temperature and salinity. This knowledge would allow them to optimally use the natural fertility of the soil, increase the efficiency of the use of means of production and make agricultural production more environmentally friendly. In their opinion the monitoring of rainfall and air temperature is no longer sufficient. Agricultural producers in Poland believe that nowadays soil properties should be assessed not only on the farm scale, but also in fields and even in fragments of a field. Creating monitoring systems would allow for rational and precise application of water, mineral fertilizers or plant protection products. It would also be easier to make decisions on scheduling work in fields and in orchards. The interviewees pointed to such solutions already functioning in Poland, but adapted to drought monitoring throughout the whole country ${ }^{40}$. Widespread monitoring of soil properties in the farm, especially of monitoring systems, requires a technical improvement in the devices for assessing soil moisture, salinity and temperature. Jones et al. ${ }^{41}$ indicate a problem that may explain why such a small percentage of farmers use soil moisture probes: the growing number of new sensors across the globe is creating a market filled with confusing choices for consumers and decreasing market share for producers. Without informed consumer choices a product price point may be controlled more by advertising advantage than by product performance and quality. Technical problems connected to the operation and servicing of such equipment are the most frequent reasons for discontinuation of their use by respondents. In the farmers' opinion, these devices must be easy to use and reliable. However, as in drought monitoring ${ }^{42}$, they should contain advanced computer applications for optimizing and verbalizing cultivation recommendations.

\section{Conclusions}

1. Currently, only $4.0 \%$ of the surveyed agricultural and horticultural farms use soil moisture, temperature and salinity probes, but as many as $80 \%$ of the respondents declare their willingness to purchase and use them. Most of the respondents report the need to purchase one probe for point measurements of soil parameters, but about $10 \%$ of respondents declared their willingness to purchase the probes in quantities that would allow for the creation of farmland monitoring systems. 
2. The price of the probes in question is not the most important purchase criterion. Farmers and horticulturists expect probes that are easy and practical to use, reliable and durable. Agricultural producers are also interested in applications that facilitate making agrotechnical decisions.

3. The obtained results prove the insufficient supply of probes meeting the expectations of agricultural producers and show a high demand for equipment with appropriate utility features. The analysis of currently available solutions shows that the market does not offer such devices. This is also confirmed by the opinions of the respondents.

4. The vast majority of farmers are aware of the importance of assessing soil moisture, temperature and salinity in optimizing irrigation, fertilization and pesticide application as well as other agrotechnical procedures.

5. Farmers using irrigation systems, as well as producers of vegetables and rape, showed a greater interest in purchasing probes. A territorial differentiation in this respect was also shown.

6. The presented results could be used by the manufacturers of soil moisture, salinity and temperature probes in order to provide devices more suited to the farmers' needs and expectations and to adjust their marketing strategies.

Received: 5 February 2021; Accepted: 21 July 2021

Published online: 17 August 2021

\section{References}

1. Iizumi, T. \& Ramankutty, N. How do weather and climate influence cropping area and intensity?. Glob. Food Sec. 4, 46-55 (2015).

2. Midgley, G. F. Plant Physiological Responses to Climate and Environmental Change. Encyclopedia of Life Sciences (John Wiley and Sons, 2017).

3. Gray, S. B. \& Brady, S. M. Plant developmental responses to climate change. Dev. Biol. 419, 64-77 (2016).

4. El-Kharbotly, A. A. \& Hokam, E. M. Some soil properties, growth parameters and crop yield as responded to soil temperature management. Egypt. J. Soil Sci. 56, 113-130 (2016).

5. Rosenzweig, C. et al. Assessing agricultural risks of climate change in the 21 st century in a global gridded crop model intercomparison. Proc. Natl. Acad. Sci. U.S.A. 111, 3268-3273 (2014).

6. Lamaoui, M., Jemo, M., Datla, R. \& Bekkaoui, F. Heat and drought stresses in crops and approaches for their mitigation. Front. Chem. 6, 26 (2018).

7. Osakabe, Y., Osakabe, K., Shinozaki, K. \& Tran, L. S. Response of plants to water stress. Front. Plant Sci. 5, 86 (2014).

8. Samarah, N. Understanding how plants respond to drought stress at the molecular and whole plant levels. Drought Stress Toler. Plants 2, 1-37 (2016).

9. Daryanto, S., Wang, L. \& Jacinthe, P. A. Global synthesis of drought effects on maize and wheat production. PLoS ONE 11(5), 1-15 (2016).

10. Zhao, C. et al. Temperature increase reduces global yields of major crops in four independent estimates. Proc. Natl. Acad. Sci. U.S.A. 114, 9326-9331 (2017).

11. Morison, J. I., Baker, N., Mullineaux, P. \& Davies, W. Improving water use in crop production. Philos. Trans. R. Soc. Biol. Sci. 363, 639-658 (2008).

12. Levidow, L. et al. Improving water-efficient irrigation: Prospects and difficulties ofinnovative practices. Agric. Water Manag. 146, 84-94 (2014).

13. Kang, S. Z. et al. Improving agricultural water productivity to ensure food security in China under changing environment: From research to practice. Agric. Water Manag. 179, 5-17 (2017).

14. Ruggiero, A. et al. Improving plant water use efficiency through molecular genetics. Horticulturae 3, 31 (2017).

15. Ponpang-Nga, P. \& Techamahasaranont, J. Effects of climate and land use changes on water balance in upstream in the Chao Phraya River basin, Thailand. Agric. Nat. Res. 50, 310-320 (2016).

16. Zhang, D. et al. Soil water balance and water use efficiency of dryland wheat in different precipitation years in response to green manure approach. Sci. Rep. 6, 26856 (2016).

17. Førland, E. J., Benestad, R., Hanssen-Bauer, I., Haugen, J. E. \& Skaugen, T. E. Temperature and precipitation development at Svalbard 1900-2100. Adv. Meteorol. 2011, 1-14 (2011).

18. Radinović, D. \& Ćurić, M. Measuring scales for daily temperature extremes, precipitation and wind velocity. Meteorol. Applic. 21, 461-465 (2014).

19. Tapiador, F. J. et al. Decorrelation of satellite precipitation estimates in space and time. Remote Sens. 10, 752 (2018).

20. Sun, Q. et al. A review of global precipitation data sets: Data sources, estimation, and inter-comparisons. Rev. Geoph. 56, 79-107 (2018).

21. Robinson, D. A., Campbell, C. S., Hopmans, J. W., Hornbuckle, B. K. \& Jones, S. B. Soil moisture measurement for ecological and hydrological watershed-scale observatories: A review. Vadose Zone J. 7, 358-389 (2008).

22. Vereecken, H. et al. On the spatio-temporal dynamics of soil moisture at the field scale. J. Hydrol. 516, 76-96 (2014).

23. Dorigo, W. A. et al. The international soil moisture network: a data hosting facility for global in situ soil moisture measurements. Hydrol. Earth Sys. Sci. Discus. 15, 1675-1698 (2011).

24. Goap, A., Sharma, D., Shukla, A. K. \& Krishna, C. R. An IoT based smart irrigation management system using Machine learning and open source technologies. Comp. Electron. Agric. 155, 41-49 (2018).

25. Barnes, A. et al. Influencing factors and incentives on the intention to adopt precision agricultural technologies within arable farming systems. Env. Sci. Policy 93, 66-74 (2019).

26. Barnes, A. P. et al. Exploring the adoption of precision agricultural technologies: A cross regional study of EU farmers. Land Use Policy 80, 163-174 (2019).

27. Eidt, C., Hickey, G. \& Curtis, M. Knowledge integration and the adoption of new agricultural technologies: Kenyan perspectives. Food Sec. 4, 355-367 (2012).

28. Busse, M. et al. Innovation mechanisms in German precision farming. Precis. Agric. 15, 403-426 (2014).

29. Bittelli, M. Measuring soil water potential for water management in agriculture: A review. Sustainability 2, 1226-1251 (2010).

30. Ramadan, K. M., Oates, M. J., Molina-Martinez, J. M. \& Ruiz-Canales, A. Design and implementation of a low cost photovoltaic soil moisture monitoring station for irrigation scheduling with different frequency domain analysis probe structures. Comp. Electron. Agric. 148, 148-159 (2018).

31. Jury, W. A. \& Vaux, H. The role of science in solving the world's emerging water problems. Proc. Natl. Acad. Sci. U.S.A. 102, $15715-15720$ (2005)

32. Regan, C. M. et al. Climate change and the economics of biomass energy feedstocks in semi-arid agricultural landscapes: a spatially explicit real options analysis. J. Envir. Manag. 192, 171-183 (2017). 
33. Zhang, X., Zhang, L., Li, K., Zhang, Y. \& Yang, G. Monitoring citrus soil moisture and nutrients using an IoT based system. Sensors 17, 447 (2017).

34. Eurostat 2018. http://ec.europa.eu/eurostat/data/database (Accessed 10 May 2020).

35. Schjønning, P. \& Lamandé, M. Models for prediction of soil precompression stress from readily available soil properties. Geoderma 320, 115-125 (2018).

36. Silva, R. P. et al. Numerical modeling of soil compaction in a sugarcane crop using the finite element method. Soil Tillage Res. 181, $1-10$ (2018).

37. Fedotov, G. N., Shoba, S. A. \& Fedotova, M. F. Influence of soil moisture and salinity on the carbon dioxide emission and water consumption during germination of cereal seeds. Eurasian Soil Sci. 51, 701-708 (2018).

38. Hu, X. W., Ding, X. Y., Baskin, C. C. \& Wang, Y. R. Effect of soil moisture during stratification on dormancy release in seeds of five common weed species. Weed Res. 58, 210-220 (2018).

39. Peerzada, A. M. \& Naeem, M. Germination ecology of Cenchrus biflorus Roxb.: Effects of environmental factors on seed germination. Rangel. Ecol. Manag. 71, 424-432 (2018).

40. Łabędzki, L. \& Bąk, B. Meteorological and agricultural drought indices used in drought monitoring in Poland: A review. Meteorol. Hydrol. Water Manag. 2, 3-13 (2014).

41. Jones, S. B., Sheng, W., Xu, J. \& Robinson, D. A. Electromagnetic sensors for water content: the need for international testing standards. ISEMA https://doi.org/10.1109/ISEMA.2018.8442316 (2018).

42. Doroszewski, A. et al. Fundamentals of the agricultural drought monitoring system. Water Environ. Rural Areas 12, 77-91 (2012).

\section{Author contributions}

Conceptualization: L.G., Data acquisition L.G., I.J., D.J., A.L., A.S., A.W., M.S., Data analysis: L.G., Design of methodology: L.G., D.J., A.L., A.S., A.W., Writing and editing: All authors helped in the writing and editing of the manuscript.

\section{Funding}

This work was funded by the Polish National Centre for Research and Development in the framework of Project No. TANGO2/340132/NCBR/2017.

\section{Competing interests}

The authors declare no competing interests.

\section{Additional information}

Correspondence and requests for materials should be addressed to L.G.

Reprints and permissions information is available at www.nature.com/reprints.

Publisher's note Springer Nature remains neutral with regard to jurisdictional claims in published maps and institutional affiliations.

Open Access This article is licensed under a Creative Commons Attribution 4.0 International License, which permits use, sharing, adaptation, distribution and reproduction in any medium or format, as long as you give appropriate credit to the original author(s) and the source, provide a link to the Creative Commons licence, and indicate if changes were made. The images or other third party material in this article are included in the article's Creative Commons licence, unless indicated otherwise in a credit line to the material. If material is not included in the article's Creative Commons licence and your intended use is not permitted by statutory regulation or exceeds the permitted use, you will need to obtain permission directly from the copyright holder. To view a copy of this licence, visit http://creativecommons.org/licenses/by/4.0/.

(C) The Author(s) 2021 